anyone involved in medical resource allocation even if paediatrics is not their problem.

D W VERE

Professor of Therapeutics, London Hospital Medical College, London E1 $2 A D$.

\section{The making of a doctor}

R S Downie and Bruce Charlton, Oxford, Oxford University Press, 1992, 203 pages, £22.50

Medical education is under increasing pressure to produce doctors who are financially accountable, wise and humane, and technically competent. The authors of this book, a lecturer in anatomy and a professor of moral philosophy, ask whether the present system is fit for the task, examine its deficiencies, and propose a series of realistic changes for the future.

The book is written in three parts. In the first section, the authors take a broad view to assess the ideological, ethical and historical background to current western medical practice, and the role of education within the profession. It emerges that medical education has evolved in a piecemeal fashion, and has a tendency to hold onto tradition even when this is not appropriate. The General Medical Council is identified as having a special role in encouraging and enforcing high standards of educational practice, but is at present hampered by a restricted range of powers.

The authors go on to consider the general aims of medicine, both intrinsic and extrinsic, and argue that medical practice has an aim, a role and a skill component: it is upon these linked concepts that education should be focused. Education itself can be distinguished from training by its emphasis on understanding, openness and flexibility, and the development of an independent caring mind.

The authors use these ideas to guide their detailed analysis of medical education, from selection to retirement, in the second section of the book. They first examine the selection process for medical school where the ever-increasing academic requirements for entry may preclude some candidates with the virtues of 'stability, warmth, reliability, kindliness and modesty': traits which are arguably most suitable for the practice of medicine.

The traditional preclinical curriculum is comprehensively criticized on the grounds of form, content and volume. The authors reiterate familiar calls for a short, relevant core curriculum in the basic medical sciences, supplemented by project work, which it is felt would make the course more scientific, clinically relevant and educational. Somewhat more radically, they make a good case for the introduction of humanities teaching, or at least for the space and time for students to follow their own 'artistic' interests, during the preclinical course. This would have a unique place in developing the imaginative and perceptive insight into the meaning of health and illness for the patient - empathy - that is often lacking in many doctors who are merely technically competent.

The authors consider basic clinical education to be generally well designed as an apprenticeship, but the pre-registration year is seriously criticized. Dr Kenneth Calman, Chief Medical Officer, writes a cogent chapter on the general aims and specific objectives of that year, identifies the areas where it is failing, and suggests in particular the need for proper supervision and feedback to the junior doctor. He goes on to consider the role and nature of continuing medical education, linking the process to clinical audit, and identify- ing the key question of how to provide effective remedial action to those who require it.

The chapter by Professor James McCormick on the contribution of general practice exhibits one problem of multi-author books in that it repeats much of the previous material. It would have been more helpful if it had focused explicitly on the possible future directions for medical education in this important area.

In the third section of the book the authors consider challenges for the future. They remark upon the changing relationship between doctors and patients in the current 'provider/ consumer' climate, and explore some of the implications for clinical freedom, and for medical education. They suggest strategies for change, in which the problems of individual and institutional inertia might be overcome by a scientific approach using limited pilot studies, with formal evaluation, before the wider introduction of new ideas. They finish with an appeal for a new emphasis on education in medical training on the grounds that 'laissez faire is a recipe for decline', and that medical education could be so much more enjoyable if it were truly educational.

This book is entertainingly written in a clear, direct style. Each chapter begins with a witty vignette and ends with a summary, enabling the reader quickly to review the developing discussion. The authors bring together arguments from history, philosophy, and educational and social theory to make a compelling case for thoughtful and pragmatic change in medical education. I felt better educated for reading this book and I recommend it to anyone engaged in the process of medical education that is, to everyone involved in medicine.

NICHOLAS JOHN ALP Wolfson College, University of Oxford. 